\title{
Investigating the Relationship of Novice Programmers' Views of Intelligence with their Motivation and Persistence
}

\author{
Jamie Gorson \\ Northwestern University \\ Evanston, IL \\ jgorson@u.northwestern.edu
}

\begin{abstract}
KEYWORDS
Growth Mindset, Self-efficacy; Motivation; Qualitative methods; Computer science education; HCI
\end{abstract}

\section{INTRODUCTION}

Software development is one of the fastest growing occupations in the United States [1], however introductory CS courses often have high dropout rates [3]. In my dissertation, I take an interdisciplinary approach inspired by psychology, learning sciences, human-computer interaction, and learning analytics theory to help address the persistence issues in CS. Specifically, I use mindset and self-efficacy theory to better understand how students' view of programming intelligence influences their motivation and behavior. The ultimate goal is to design environmental supports for undergraduate CS students that encourage motivation and persistence.

\section{LITERATURE REVIEW}

Students' self-assessment of their programming ability can shape their decision to major in CS [9]. Lewis et al. found that students judge their ability based on three criteria: prior experiences, speed of programming, and grades. Another study found that students' emotional reactions to programming episodes do not always align with the outcome and students may react negatively when their expectations for performance are not met [8]. For example, a student who believes that speed is important and finishes a programming problem correctly, but slowly, may negatively evaluate her ability if she expected to finish the problem quickly. Both of these studies suggest that the criteria students use to evaluate their intelligence impacts their behaviors and emotional reactions. This is magnified in introductory undergraduate CS because students more frequently evaluate their intelligence when they are new to the field and have the pressure of deciding if they should major in CS [2].

Students' mindsets about the malleability of programming intelligence might also contribute to their motivation and behavior. Studies show that students who believe that intelligence is an inborn trait (fixed mindset) value proving their intelligence over learning, and are more likely to give up when challenged in order to avoid failure $[6,7]$. In contrast, students who believe that intelligence is malleable (growth mindset) value learning over performance, and

Permission to make digital or hard copies of part or all of this work for personal or classroom use is granted without fee provided that copies are not made or distributed for profit or commercial advantage and that copies bear this notice and the full citation on the first page. Copyrights for third-party components of this work must be honored.

For all other uses, contact the owner/author(s).

ICER '19, August 12-14, 2019, Toronto, ON, Canada

(C) 2019 Copyright held by the owner/author(s).

ACM ISBN 978-1-4503-6185-9/19/08.

https://doi.org/10.1145/3291279.3339443 tend to persist in the face of challenges [6]. Researchers have developed interventions that promote the growth mindset, which have shown to improve student persistence and performance $[4,12]$.

Unfortunately, multiple studies in the CS domain have been unsuccessful in applying the traditional mindset interventions, finding little to no effect on students' mindsets or behaviors [5, 11]. For example, Cutts et al.'s intervention successfully changed students mindsets on surveys, but did not find any change in course performance [5]. For the interventions with small effects, we don't know what mechanisms lead to mindset and behavior change because the interventions were complicated and not replications of previous mindset interventions. For example, Loksa et al. designed an intervention for CS youth camps that taught students problem-solving skills [10]. They found that students in a control group became more fixed mindset over the course of the camp, but encouragingly saw no significant change in mindsets for the intervention group. It is unclear what aspects of Loksa et al.'s intervention produced these effects, and whether they were a result of student mindsets, the problem-solving scaffolds, or student age.

In order to design more effective and scalable interventions in CS, we need to understand students' perspectives on programming intelligence and how it relates to their mindset, motivation, emotional reactions and behaviors while programming.

\section{RESEARCH PROGRESS \& PLAN}

I propose a dissertation that contributes to our understanding of undergraduate, novice programmers through three projects that build on each other. I have already completed the first project, which was an exploratory, qualitative study with the goal of better understanding the application of mindset theory in CS and identifying other contributing factors to mindset's impact on persistence in undergraduate CS students. In the first study, we found that students were constantly evaluating their ability while programming, and used a variety of self-assessment criteria. In the second project, I plan to explore the relationship between students' mindsets, self-assessment criteria and their behaviors and reactions while programming. In the final project, I plan to apply what I learned in the previous studies to design environmental supports to influence students' views of programming intelligence and student motivation.

For the first project, I designed a methodological approach that applies qualitative analysis. Qualitative analysis has not been previously used to explore mindset theory, but ICER authors have used it to describe and understand the novice programming experience. The approach has three parts: (1) a challenging programming problem, (2) a survey, and (3) an interview about their CS experience, programming intelligence, and mindset. The challenging programming task provides data about programming behaviors 
and is important for eliciting feelings about programming intelligence. The task influences the interview because studies show that mindset is only relevant to behaviors when students are challenged [6]. We will extend this method in future projects. For example, we plan to add multimodal technology, like skin conductance and facial emotion recognition, to surface students' emotional reactions and better understand programming behaviors.

\subsection{Project 1: Exploratory Research}

We (my advisor and I) have already conducted Project 1 of the dissertation. Our goal for the project was to study how students' talk about programming intelligence reflected (1) mindset, (2) behaviors associated with mindset, e.g. persistence and reaction to challenge, and (3) other motivational factors. We used our qualitative method to collect data. Our analysis focused on the interview component of the study, where we asked indirect questions about programming intelligence to gain insight into students' mindsets and behaviors.

We found that students' mindsets rarely aligned with the definitions in the literature; some students presented mindsets that combined fixed and growth attributes, while others behaved in ways that did not align with their mindset. These findings are surprising because mindset theory is robust and has been proven in many different domains and contexts. As a result, we suspect that other motivational factors may interact with mindset to produce these inconsistencies. In the interviews, we noticed that students frequently evaluated their programming ability, often using surprising criteria, such as typing speed and ease of debugging.

To further explore the existence and characteristics of the selfassessment criteria, we conducted a survey study to understand if (1) these same criteria exist in a larger sample of students, (2) other self-assessment criteria arose that we did not find in the interview study and (3) there is consistency or variation in the criteria that students use to measure programming ability. We identified 14 selfassessment criteria. We found that for some of the self-assessment criteria, there was large variation in students' responses, yet for other criteria, students responded consistently. We suggest that the frequent self-evaluations encourage students' self-assessment criteria to interact with the application of mindset theory on programming behaviors in CS, which we explore in project 2 .

\subsection{Project 2: Theory Building}

In Project 1, we identified that students frequently evaluated their programming intelligence. In Project 2, we plan to explore the relationship between how students evaluate their programming intelligence and their approach to programming, meaning their programming behaviors as well as their emotional reactions to programming events. Learning about this relationship will help us to understand how students' perceptions of programming intelligence change behavior and impact motivation and persistence. We will consider both students' mindset and self-assessment criteria when studying their perceptions of programming intelligence.

For this study, we plan to use an extended version of our qualitative interview method. We will incorporate the survey used in the survey study from the first project into the qualitative study. Additionally, we will adjust the interview questions to explore the relationship between self assessment criteria and programming behaviors. Finally, we will incorporate multimodal technology to collect better data on emotions while programming, through skin conductance and emotion recognition. By the end of the second project, we hope to know more about the relationship between students' approach to programming, the self-assessment criteria and their mindsets about the malleability of programming intelligence.

\subsection{Project 3: Design Research}

In the third project, we will use the findings from the first two projects to help answer the research question: How do we design environmental supports to help students develop positive and productive views about programming intelligence? The environmental supports could take a variety of forms, including adding features to the students' development environment or providing strategies to instructors and teaching assistants. We hypothesize that an environment that encourages the growth mindset and productive self-assessment criteria will impact students' approach to programming. The hypothesis is rooted in the findings from the first two studies. We will evaluate our design based on how it impacts students' behaviors and emotional reactions, including changes in persistence and motivation in the CS domain.

\section{REFERENCES}

[1] 2018. Occupational Outlook Handbook. (April 2018). https://www.bls.gov/ooh/ fastest-growing.htm

[2] Albert Bandura. 1982. Self-efficacy mechanism in human agency. American psychologist 37, 2 (1982), 122.

[3] Theresa Beaubouef and John Mason. 2005. Why the high attrition rate for computer science students: some thoughts and observations. ACM SIGCSE Bulletin 37, 2 (June 2005), 103. https://doi.org/10.1145/1083431.1083474

[4] Lisa S. Blackwell, Kali H. Trzesniewski, and Carol S. Dweck. 2007. Implicit theories of intelligence predict achievement across an adolescent transition: A longitudinal study and an intervention. Child development 78, 1 (2007), 246-263. http://onlinelibrary.wiley.com/doi/10.1111/j.1467-8624.2007.00995.x/full

[5] Quintin Cutts, Emily Cutts, Stephen Draper, Patrick O'Donnell, and Peter Saffrey. 2010. Manipulating mindset to positively influence introductory programming performance. In Proceedings of the 41st ACM technical symposium on Computer science education. ACM, 431-435. http://dl.acm.org/citation.cfm?id=1734409

[6] Carol S Dweck. 2006. Mindset: The new psychology of success. Random House Incorporated.

[7] Carol S. Dweck and Ellen L. Leggett. 1988. A social-cognitive approach to motivation and personality. Psychological review 95, 2 (1988), 256

[8] Päivi Kinnunen and Beth Simon. 2012. My program is ok -am I? Computing freshmen's experiences of doing programming assignments. Computer Science Education 22, 1 (March 2012), 1-28. https://doi.org/10.1080/08993408.2012.655091

[9] Colleen M. Lewis, Ken Yasuhara, and Ruth E. Anderson. 2011. Deciding to major in computer science: a grounded theory of students' self-assessment of ability. In Proceedings of the seventh international workshop on Computing education research. ACM, 3-10.

[10] Dastyni Loksa, Andrew J. Ko, Will Jernigan, Alannah Oleson, Christopher J. Mendez, and Margaret M. Burnett. 2016. Programming, Problem Solving, and Self-Awareness: Effects of Explicit Guidance. ACM Press, 1449-1461. https: //doi.org/10.1145/2858036.2858252

[11] Beth Simon, Brian Hanks, Laurie Murphy, Sue Fitzgerald, Renée McCauley, Lynda Thomas, and Carol Zander. 2008. Saying isn't necessarily believing: influencing self-theories in computing. In Proceedings of the Fourth international Workshop on Computing Education Research. ACM, 173-184. http://dl.acm.org/citation.cfm? id $=1404537$

[12] David S. Yeager, Carissa Romero, Dave Paunesku, Christopher S. Hulleman, Barbara Schneider, Cintia Hinojosa, Hae Yeon Lee, Joseph O’Brien, Kate Flint, Alice Roberts, Jill Trott, Daniel Greene, Gregory M. Walton, and Carol S. Dweck. 2016. Using design thinking to improve psychological interventions: The case of the growth mindset during the transition to high school. Fournal of Educational Psychology 108, 3 (2016), 374-391. https://doi.org/10.1037/edu0000098 